\title{
Psychotropic Use and Associated Neuropsychiatric Symptoms among Patients with Dementia in the United States
}

\author{
Running head: Psychotropic Use and Neuropsychiatric Symptoms \\ Donovan T. Maust, MD, $\mathrm{MS}^{1,2,3}$, Kenneth M. Langa, MD, $\mathrm{PhD}^{2,3,4,5}$, Frederic C. Blow, $\mathrm{PhD}^{1,2,3}$, \\ and Helen C. Kales, $\mathrm{MD}^{1,2,3}$ \\ ${ }^{1}$ Department of Psychiatry, University of Michigan, Ann Arbor, MI \\ ${ }^{2}$ Center for Clinical Management Research, VA Ann Arbor Healthcare System, Ann Arbor, MI \\ ${ }^{3}$ Institute for Healthcare Policy and Innovation, University of Michigan, Ann Arbor, MI \\ ${ }^{4}$ Department of Internal Medicine, University of Michigan, Ann Arbor, MI \\ ${ }^{5}$ Institute for Social Research, University of Michigan, Ann Arbor, MI
}

\section{Corresponding Author:}

Donovan TMaust, MD, MS

Department of Psychiatry

NCRC 016-222W

2800 Plymouth Rd

Ann Arbor MI 48109

maustd@umich.edu

(o) 734.615 .4356

(f) 734.764 .7932

The authors have no competing interests.

Funding Source: This work was funded by the Beeson Career Development Award Program (NIA K08 AG048321, the American Federation for Aging Research, The John A. Hartford Foundation, and The Atlantic Philanthropies). The Health and Retirement Study is funded by the National Institute on Aging (U01 AG009740) and performed at the Institute for Social Research, University of Michigan, Ann Arbor.

Keywords: dementia, neuropsychiatric symptoms, behavioral and psychological symptom, antipsychotic, antidepressant, benzodiazepine

\section{Key Points:}

- In a nationally-representative sample, over $40 \%$ of patients with dementia were prescribed a psychotropic medication.

- The burden of neuropsychiatric symptoms is highest among those on antipsychotics and sedative-hypnotics.

This is the author manuscript accepted for publication and has undergone full peer review but has not been through the copyediting, typesetting, pagination and proofreading process, which may lead to differences between this version and the Version of Record. Please cite this article as doi: 
- Controlling for level of neuropsychiatric symptoms, caregiver distress, and dementia stage, nursing home residence was the characteristic most strongly associated with psychotropic use.

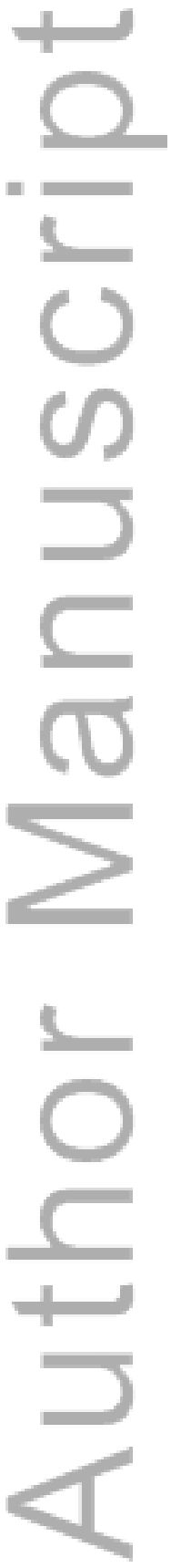




\section{ABSTRACT}

Objective: To determine the national prevalence of psychotropic use and association with neuropsychiatric symptoms among patients with dementia.

Methods: Participants diagnosed with dementia $(n=414)$ in the Aging, Demographics, and Memory Study, a nationally-representative survey of US adults $>70$ years old. Diagnosis was based on in-person clinical assessment and informant interview. Information collected included demographics, place of residence, 10-item Neuropsychiatric Inventory (NPI), and prescribed medications (antipsychotic, sedative-hypnotic, antidepressant, mood stabilizer).

Results: Of 414 participants with dementia, $41.4 \%$ were prescribed a psychotropic medication, including $84.0 \%$ of nursing home residents and $28.6 \%$ of community-dwellers. $23.5 \%$ were prescribed an antidepressant. Compared to the total NPI score of those on no medication (4.5), those on antipsychotics and those on sedative-hypnotics had much higher scores (respectively: 12.6, $p<0.001 ; 11.8, p=0.03)$, though those antidepressants did not $(6.86, p=0.15)$. A larger proportion of patients on antipsychotics exhibited psychosis and agitation compared with those on no medication, while those on antidepressants exhibited more depressive symptoms. In multivariable logistic regression that included dementia severity and nursing home residence, nursing home residence was the characteristic most strongly associated with psychotropic use (odds ratio ranging from $8.96[p<0.001]$ for antipsychotics to $15.59[p<0.001]$ for sedativehypnotics). More intense psychotic symptoms and agitation were associated with antipsychotic use; more intense anxiety and agitation were associated with sedative-hypnotic use. More intense depression and apathy were not associated with antidepressant use.

This article is protected by copyright. All rights reserved. 
Conclusions: In this nationally-representative sample, $41.4 \%$ of patients were taking psychotropic medication. While associated with NPS, nursing home residence was most strongly tied to use.

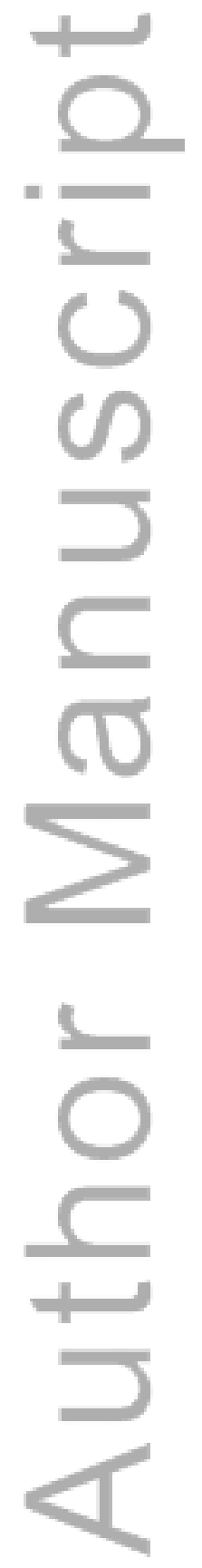




\section{INTRODUCTION}

Dementia affects a large and growing number of older adults (Plassman et al., 2007). Although cognitive impairment is the clinical hallmark of dementia, neuropsychiatric symptoms (NPS) are exceedingly common and often dominate disease presentation (Kales et al., 2015). NPS occur in dementia of all types in clusters or syndromes such as depression, psychosis, agitation, and apathy (Lyketsos et al., 2011). Thirty percent of the cost of caring for communitydwelling patients with dementia is directly attributable to NPS management (Schnaider Beeri et al., 2002), while just 1 or 2 NPS symptoms are associated with an additional 10 hours weekly (a doubling) of active help from caregivers (Okura and Langa, 2011). Such symptoms, as opposed to core cognitive symptoms, often create the most difficulties for patients, caregivers, and providers, and lead to earlier nursing home placement (Yaffe et al., 2002). Psychotropic use in patients with dementia is an area of intense interest, given the distressing nature of NPS thought to trigger medication use, limited evidence of benefit from medications, and evergrowing evidence of harms associated with use, both for older adults in general (American Geriatrics Society, 2015, Beers, 1997) and patients with dementia in particular (Schneider et al., 2005, Maust et al., 2015). While prescribing in the nursing home has been an area of significant attention, a recent report from the Government Accountability Office noted that less is known about antipsychotic prescribing in the community (US Government Accountability Office, 2015).

Studies of psychotropic use in patients with dementia often come from large administrative or claims data such as Medicare or the Veterans Affairs system (Kales et al., 2011, Huybrechts et al., 2011) and have two key limitations. First, the use of psychotropic medications in patients with dementia in these observational analyses is generally presumed to be for treating NPS, though this assumption has not been specifically tested. NPS are generally 
not billed for nor documented as part of routine clinical care in a manner that is easily accessible for research purposes. In addition, the sensitivity and specificity of a dementia diagnosis in observational data are limited and may lead to mis-classification and bias, as mild dementia cases may be excluded or delirium cases may be inappropriately classified as having dementia (Taylor et al., 2009). One previous study in a representative US sample of patients with clinically-diagnosed dementia examined the association between NPS and antipsychotic use and, surprisingly, did not find a significant association (Rhee et al., 2011).

This analysis uses the Aging, Demographics, and Memory Study (ADAMS) (Langa et al., 2005), a sub-study of the Health and Retirement Study (HRS). ADAMS is a survey of all US adults over the age of 70 designed to derive nationally-representative estimates of both prevalent and incident dementia. We first estimate the prevalence of antipsychotic, sedativehypnotic, antidepressant, and mood stabilizer use among adults with dementia and describe the clinical characteristics associated with use, focusing on NPS. In light of limited evidence that psychotropic medications effectively treat NPS (Kales et al., 2015), we hypothesized that prescribing would be associated with higher overall NPS prevalence. In addition, we hypothesized the following symptom-medication associations: delusions, hallucinations, and agitation with antipsychotics; anxiety and agitation with sedative-hypnotics; and depression and apathy with antidepressants. We included the NPS domain of apathy in the antidepressant analysis as there is a significant overlap in symptoms between depression and apathy, while caregivers and even providers may not distinguish the two (Landes et al., 2001). 


\section{METHODS}

\section{Sample}

The ADAMS (Langa et al., 2005) sample was drawn from the larger Health and Retirement Study (HRS), an ongoing, nationally-representative sample of individuals $>50$ years that began in 1992 (Sonnega et al., 2014). ADAMS was designed to provide nationally representative data on the antecedents, prevalence, outcomes, and costs of dementia and began with a stratified random subsample of 1,770 individuals selected from HRS respondents >70 years of age who completed the 2000 or 2002 HRS wave. Of those HRS respondents selected for participation, 856 (56\% of eligible, living participants) consented to the ADAMS baseline assessment (Wave A) that was conducted from 2001 to 2003.

Participants completed a 3- to 4-hour assessment by a nurse and neuropsychology technician in their residence. As summarized by Plassman et al. (Plassman et al., 2011), a knowledgeable informant (usually a spouse or adult child) was identified to provide the following: (1) detailed history and current assessment of cognition and function; (2) medical history; (3) current medications; and (4) current NPS. The informant was a spouse or a child in $73 \%$ of cases and lived with the participant in $53 \%$ of cases (Okura et al., 2010). Each participant completed neuropsychological measures and a neurological examination. The same assessment was performed for all participants and informants, including nursing home residents. The ADAMS multi-specialty consensus panel reviewed all information from the inperson evaluation and relevant medical records. The dementia diagnosis was made using criteria from the Diagnostic and Statistical Manual of Mental Disorders (DSM)-III-R and DSM-IV. As part of the purpose of ADAMS was to understand incident dementia, 3 follow-up waves (Waves B-D) were completed at two-year intervals, with the same information collected 
as for Wave A. Final assessments (Wave D) began in 2008. Participants selected for follow-up were generally patients who had not yet been diagnosed with dementia; participants diagnosed with dementia did not undergo follow-up. The sample for the present analysis includes all 414 participants (of 856 consenting participants at baseline) that received a final diagnosis of dementia during either the baseline assessment $(n=308)$ or follow-up $(n=40,47$, and 19 for waves $B, C$, and $D$, respectively). The data used for analysis is from the Wave at which the participant was diagnosed with dementia.

The institutional review boards at the University of Michigan and Duke University Medical Center approved all study procedures; study participants or surrogates provided informed consent. ADAMS data are available online (http://hrsonline.isr.umich.edu/index.php).

\section{Measurements}

\section{Dementia Assessment and Diagnosis}

The consensus panel determined the presence of dementia, which was subtyped into: Alzheimer's dementia (McKhann et al., 1984), vascular dementia (Román et al., 1993), or other. Dementia severity was classified using the Clinical Dementia Rating Scale (CDR) (Morris, 1993). As in prior studies, mild dementia was defined as a CDR stage of 0.5-1.0, moderate as CDR 2.0, and severe as CDR 3.0-5.0 (Okura et al., 2010, Lyketsos et al., 2000). Testing included the Mini-Mental State Examination (MMSE) (Folstein et al., 1975); please refer to Langa et al. (Langa et al., 2005) for the full neuropsychological battery.

\section{Sociodemographic Characteristics}


The analysis includes participant age, sex, ethnicity, education, and nursing home residence.

\section{Medical History}

Informants were asked if the participant had history of the following: stroke, fall, seizure disorder, hypertension, heart attack, diabetes, chronic respiratory problems, cancer, alcohol use, tobacco use, bipolar disorder, or schizophrenia. In addition, the informants were asked whether, in the participant's lifetime, they had experienced $a \geq 2$ week period of depressed mood or anhedonia, along with follow-up questions to determine if the participant met DSM-IV criteria for a lifetime history of a major depressive episode. Informants were also asked if the participant had ever seen a psychiatrist for a "memory problem" or for "concerns with his/her memory or thinking."

\section{Medications}

Participants (or the designated informant) were mailed a medication form prior to the ADAMS visit and asked to have information available at the time of assessment for medications used in the previous two weeks; the study nurse examined medication containers for confirmation. We determined the total number of medications used and classified psychotropics as follows: antipsychotic, sedative-hypnotic, antidepressant, and mood stabilizer (please see eTable 1 for medications and specific exclusions). We also determined whether they were on a cholinesterase inhibitor or memantine.

Neuropsychiatric Symptoms 
NPS were assessed using the 10-item Neuropsychiatric Inventory (NPI) (Cummings, 1997). Informants were asked whether, in the past month, the participant exhibited symptoms from 10 domains: delusions, hallucinations, agitation/aggression, depression, apathy, elation, anxiety, disinhibition, irritability, and aberrant motor behaviors. If informants answered "yes" to the domain-specific screening item, they were asked follow-up questions to confirm presence of the symptom. If confirmed, participants were asked to rate frequency on a 4-point scale and severity on a 3-point scale. Each NPI domain then received a score equal to frequency $x$ severity, yielding a domain range of 0-12 and a total NPI score of 0-120. After describing each NPI domain, the informant was asked, "How emotionally distressing do you find this behavior?" on a scale from 0 to 5, yielding a NPI caregiver distress score of 0-50.

\section{Analyses}

Population sample weights were constructed to account for probability of selection in the stratified longitudinal sample design and to adjust for differential participation and non-response in ADAMS for each assessment wave (Heeringa et al., 2009). Using the longitudinal weight allows the ADAMS sample to be nationally representative of older adults $>70$ years old with dementia from 2002-2008.

We estimated the proportion of participants with dementia on psychotropic medication and the number of persons this represents nationally. We compared demographic and clinical characteristics of each medication group with the non-user group using an adjusted Wald test. For participants prescribed medication from several groups, we used an antipsychotic > sedative-hypnotic > antidepressant hierarchy to assign the participant to one mutually exclusive group (e.g., a respondent prescribed risperidone and lorazepam was assigned to the 
antipsychotic group). Mood stabilizers were included in the antipsychotic group for analysis given: 1) the small number of participants that reported mood stabilizers $(n=13) ; 2)$ evidence that mood stabilizers have been used as an alternative to antipsychotics in patients with dementia (Kales et al., 2011); and 3) the mortality risk associated with mood stabilizers is similar to antipsychotics (Kales et al., 2012).

= We then created logistic regression models to examine the association of NPS with psychotropic medication use. First, for each medication group, we used the NPS burden (symptoms present on 0, 1-2, $\geq 3$ NPI domains, following Okura et al. (Okura and Langa, 2011, Okura et al., 2010)) as the primary predictor in a logistic regression predicting the odds of medication use. Initial models adjusted for age, gender, and survey year to account for secular trends in the use of medication; final models included nursing home residence and dementia stage. Finally, we created logistic regression models to explore the association between specific hypothesized NPS clusters and medication use, adjusting for caregiver distress. Analyses were performed in Stata 13.1 (StataCorp LP, College Station, TX) using two-sided tests of statistical significance, with a $\mathrm{P}$ value $<0.05$ considered statistically significant.

We performed a variety of sensitivity analyses. First, we ran the final regression models limiting the NPS domain prevalence categories to clinically significant symptoms (NPI domain score $\geq 4$ ) as opposed to simply prevalent NPS. In addition, we tested the models using nonexclusive medication groups. Finally, we tested the adjusted regression models with the following alternative medication groups: 1) antipsychotics excluding mood stabilizers; 2) benzodiazepines excluding other sedative-hypnotics; and 3) antidepressants limited to only selective serotonin and serotonin-norepinephrine reuptake inhibitors. 


\section{RESULTS}

In this nationally representative sample of patients with dementia, 41.4\% (95\% confidence interval [Cl] 35.4-47.6\%) were on at least one psychotropic medication, representing 2.8 million people ( $\mathrm{Cl}$ 2.0-3.5 million). Overall, $23.1 \%(\mathrm{Cl} 16.6-31.2 \%)$ of these participants with dementia resided in a nursing home. Psychotropic users comprised $84.0 \%(\mathrm{Cl} 76.2-89.5 \%)$ of nursing home residents and $28.6 \%$ (Cl 20.9-37.8\%) of community-dwellers. Antidepressants were the most commonly prescribed medication (Table 1), followed by sedative-hypnotics, antipsychotics, and mood stabilizers. $14.7 \%$ (Cl 10.2-20.8\%) of participants were on benzodiazepines, which comprised the majority of sedative-hypnotic prescriptions.

Table 2 presents demographic and clinical characteristics of patients with dementia, classified by psychotropic group. The groups were similar across most demographic characteristics, though patients residing in nursing homes comprised a larger share of every psychotropic group than those on no psychotropic medication. The antipsychotic group had larger proportions of patients with both moderate and severe dementia than the no medication group, as well as an MMSE score that was 6 points lower (13.2 [Cl 10.3-16.1] v. 19.2 [Cl 17.720.6]; $F=12.27, p=0.0017)$. Informants reported that the vast majority of patients in all groups had never seen a psychiatrist to evaluate their memory or thinking.

Participants in the antipsychotic and sedative-hypnotic groups had significantly higher total NPS. The estimated prevalence of NPI domains by medication group is shown in Figure 1 (see eFigure 1 for average domain scores). Compared with those on no medication, a larger proportion of participants on antipsychotics exhibited delusions (40.6\% [Cl 16.2-64.9\%] v. 7.4\% [1.5-13.4\%]; F=8.25, p=0.008), hallucinations (29.9\% [Cl 6.7-53.1\%] v. 6.4\% [0.3-12.5\%]; $\mathrm{F}=4.25, \mathrm{p}=0.05)$, and agitation $(34.1 \%$ [Cl 15.8-52.4\%] v. 12.0\% [Cl 5.5-18.6\%]; F=6.30, 
$\mathrm{p}=0.02$ ). The sedative-hypnotic group had a higher prevalence of delusions than those on no medication (31.8\% [Cl 6.4-57.2\%] v. 7.4\% [1.5-13.4\%]; F=4.49, p=0.04). Depression was more prevalent among those on antidepressants than the no medication group $(51.9 \%[\mathrm{Cl} 34.6$ 69.3\%] v. $18.7 \%$ [10.4-26.9\%]; $F=13.34, p=0.001)$.

Logistic regression models estimating the association between overall NPS burden (i.e., prevalent symptoms) and medication use are presented in Table 3. In initial models, the highest category of NPS burden (symptoms in $\geq 3$ categories) was associated with significantly increased odds of medication use for all groups. In final models that included nursing home residence and dementia severity, the characteristic most strongly associated with increased odds of medication use was nursing home residence. When NPS burden was limited to clinically significant symptoms (eTable 2), the association between NPS burden and psychotropic use was attenuated for all groups but antipsychotics. When overlap was allowed between psychotropic groups (eTable 3 ), NPS burden at $\geq 3$ domains was associated with use for all 3 groups. Nursing home residence was still the characteristic most strongly associated with psychotropic use in these sensitivity analyses, as well as using the more narrowly-defined medication groups.

The association of specific NPS clusters with medication use is presented in Table 4. As hypothesized, additional symptom intensity of delusions, hallucinations, or agitation was associated with antipsychotic use, while additional anxiety or agitation was associated with sedative-hypnotic use. However, more intense depression and apathy were not associated with antidepressant use. Caregiver distress was not significantly associated with any class of psychotropic use. Again, nursing home residence was the characteristic most consistently associated with use across psychotropic groups. Using overlapping medication groups had 
limited effect on the general magnitude and statistical significance of findings (eTable 4), as was also the case with sensitivity analyses using more narrow medication groups.

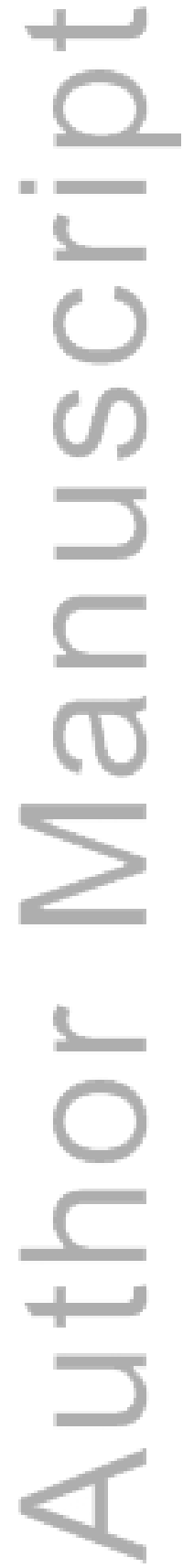




\section{DISCUSSION}

In this nationally representative sample, over $40 \%$ of patients diagnosed with dementia based on an in-depth clinical assessment were taking a psychotropic medication, including $84 \%$ of nursing home residents with dementia and $29 \%$ of those in the community. Both the overall and community-based rates are far higher than the rate of $11.1 \%$ among the US adult population described by Paulose-Ram et al. (Paulose Ram et al., 2007) using data from the National Health and Nutrition Examination Survey (NHANES) at a comparable time, though NHANES does not include nursing home patients. They found prevalence of individual medication classes as follows: antidepressant (8.1\%), sedative-hypnotic (3.5-3.8\%), antipsychotics (0.8-1.0\%), and mood stabilizers (0.3-0.4\%). In contrast, we found the following prevalence among participants with dementia: antidepressants (23.5\%), sedative-hypnotic (18.2\%), antipsychotic (11.1\%), and mood stabilizers (1.5\%). Even excluding nursing home medication users from each group, these remain high rates of psychotropic medication use for any group, especially adults with an average age over 80 . The rate of cholinesterase inhibitor and memantine use found is consistent with analyses from the Medicare Current Beneficiary Survey from a similar time period (Gruber-Baldini et al., 2007).

This high rate of psychotropic utilization is most likely an attempt to address dementiaassociated NPS, despite limited evidence of benefit (Kales et al., 2015). The prevalence of NPI domains and the average NPI score among the ADAMS participants with dementia were similar to other population-based studies (Lyketsos et al., 2000, Lyketsos et al., 2002) though the NPI total among medication users was relatively low compared to medication trials (Banerjee et al., 2011, Schneider et al., 2006). Our analysis, however, is the first to confirm the assumption that 
psychotropic use is associated with patient NPS burden. As hypothesized, more intense symptoms of psychosis and agitation were associated with antipsychotic use, while more intense anxiety and agitation were associated with sedative-hypnotic use. Use of antidepressants was associated with higher prevalence of NPS domains but not, however, with more intense depression or apathy. It may be that antidepressants effectively treat these symptoms, but the high prevalence of depressive symptoms among ADAMS participants as well as clinical trial evidence would suggest otherwise (Rosenberg et al., 2010, Banerjee et al., 2011). Alternatively, as the most commonly used medication for this population, antidepressants are possibly being used broadly and non-specifically to treat NPS. Finally, some evidence suggests that antidepressants are prescribed in the absence of any significant mental diagnosis or symptoms altogether, which may be true for these ADAMS participants, as well (Takayanagi et al., 2015, Maust et al., 2011). This is particularly concerning, as antidepressants were the most commonly prescribed class of medication, used in nearly one quarter of the sample. The strong association between residing in a nursing home and psychotropic use of all types suggests that efforts to minimize antipsychotic prescribing in nursing homes are critical. It will be important to study whether this has simply led to a compensatory increase in other psychotropic use. To our surprise, additional caregiver distress was not associated with psychotropic use in our models.

To our knowledge, the only prior analysis to examine the association of NPS and psychotropic use (antipsychotics specifically) in a nationally-representative clinical sample used baseline Wave A ADAMS data (Rhee et al., 2011) and, surprisingly, the authors did not find an association between neuropsychiatric symptoms and antipsychotic use. However, we believe there are two key distinctions that account for this discrepancy. First, their logistic regression 
compared antipsychotic users to non-antipsychotic users, whereas our analyses compared antipsychotic users to those with no psychotropic medication use. Given our findings of the relatively high prevalence (count of NPI domains) and burden (NPI total) of NPS among the sedative-hypnotic users, it follows that the association between NPS and antipsychotic use would be attenuated/absent when sedative-hypnotic users were included in the comparison group. Second, they used the NPI in an unconventional manner by counting domains and then using this as a continuous measure (range: 0-10). As such, they report a "Neuropsychiatric Inventory, mean" among antipsychotic users of just 2.16 (this is the reported NPI total, not a single domain score) and 1.35 among non-antipsychotic users. This NPI measure is then used as a continuous variable in the logistic regression. It is not surprising, then, that their regression model would find no association between a 1-unit change in NPI on this continuous scale and antipsychotic use, as the groups differed by just 0.81 units (i.e., 2.16 minus 1.35 ). Ultimately, we attempted to construct variables and models in a manner that most accurately captures and then tests the hypothesized associations between NPS and prescribing in clinical practice.

The key limitation of this work is its cross-sectional nature: we cannot address change in medication use and corresponding change in NPS burden, nor do we know the prescribers' rationale for prescribing or plans to adjust. In addition, some of the psychotropic use may reflect treatment for a long-standing mental illness rather than the more recent development of NPS (e.g., antidepressants for Major Depressive Disorder prior to development of dementia). Another limitation is that several years have passed since ADAMS was completed, and there has possibly been a shift in psychotropic use since that time. Those patients with prevalent dementia were drawn from the baseline survey, while the subsequent (incident) cases added to the sample were less likely to have advanced disease. However, it is unlikely that the overall 
prevalence of psychotropic use has declined much—Kales et al.'s analysis of antipsychotic trends using national VA administrative data found a relatively constant rate of overall psychotropic use (Kales et al., 2011). There may have been shifts in the type of psychotropic used, as they found a small shift away from antipsychotics following the 2005 FDA black-box warning (US Food and Drug Administration, 2005) and an increase in use of other psychotropic agents, including anticonvulsants. Antipsychotic use among dementia patients in nursing homes has declined somewhat recently, likely in response to a concerted two-year effort initiated by the Centers for Medicare and Medicaid Services associated with a 15.1\% reduction (US Government Accountability Office, 2015). However, it is unknown if community prescribing of antipsychotics to patients with dementia in the US has changed; use overall among adults has actually increased (Olfson et al., 2012). As noted above, it is likely that any decrease in antipsychotics would have been accompanied by a compensatory increase in the use of other psychotropic medication as clinicians shift to alternative strategies to manage NPS (Porsteinsson et al., 2014). While evidence regarding the risks associated with psychotropic prescribing in dementia has grown since the ADAMS study period, there have been few advances in the structure of care delivery or payment that would have encouraged more robust delivery of behavioral interventions and substantially reduced psychotropic treatment. Finally, the ADAMS participation rate was $56 \%$, though this is comparable to other population studies of older age groups (Tell et al., 1993, Rockwood et al., 2004). Sampling weights were derived to account for non-response bias, and U.S. population estimates for older adults derived from ADAMS closely match the U.S. Census Bureau (Plassman et al., 2008).

Each class of psychotropic medication studied is associated with a range of risks for older adults (American Geriatrics Society, 2015), from nausea or hyponatremia with a selective 
serotonin reuptake inhibitor (SSRI) (Banerjee et al., 2011) to more serious consequences such as falls with benzodiazepines (Wang et al., 2001) and mortality with antipsychotics (Schneider et al., 2005). Potential harms associated with antipsychotic alternatives should not be minimized, as even SSRI-related nausea could be distressing to a patient with cognitive impairment and potentially exacerbate NPS, leading to the perceived need for more medication. While NPS are distressing, caregivers, providers, and facilities caring for these patients need to realistically consider whether there is sufficient evidence of benefit to justify this high rate of psychotropic use.

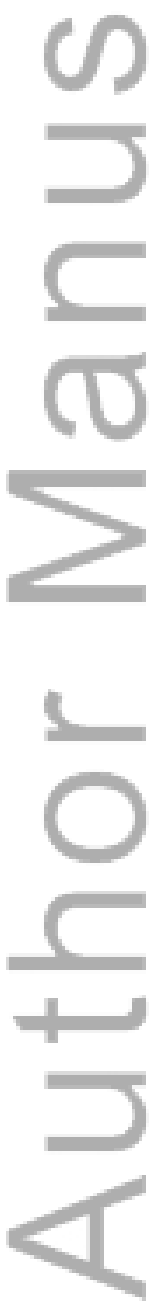




\section{ACKNOWLEDGMENTS}

The authors would like to acknowledge Ryan McCammon for his input regarding use and analysis of ADAMS data.

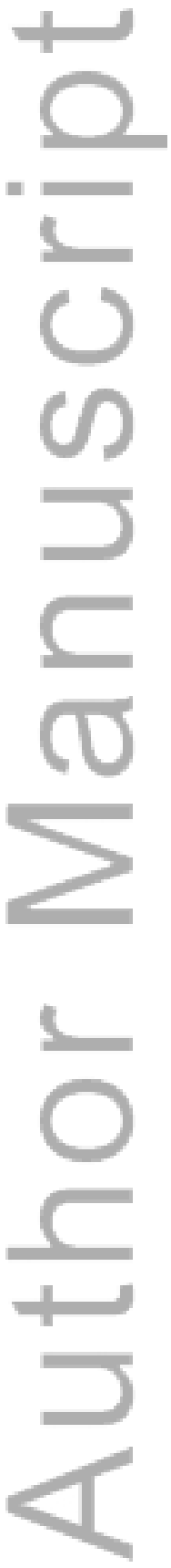


Table 1. National Prevalence Estimates of Psychotropic Medication ${ }^{\mathrm{a}}$ Use in Patients with Dementia from the Aging, Demographics, and Memory Study $(n=414)$

\begin{tabular}{|c|c|c|c|c|c|}
\hline$\infty$ & None & Antipsychotic & Sedative-Hypnotic & Antidepressant & Mood Stabilizer \\
\hline Participants, n & 234 & 56 & 70 & 103 & 13 \\
\hline $\begin{array}{l}\text { Overall weighted } \\
\text { percent }(95 \% \mathrm{Cl})\end{array}$ & $\begin{array}{c}58.6 \\
(52.4-64.6)\end{array}$ & $\begin{array}{c}10.9 \\
(7.6-15.3)\end{array}$ & $\begin{array}{c}19.5 \\
(14.2-26.2) \\
\end{array}$ & $\begin{array}{c}23.5 \\
(18.8-29.0) \\
\end{array}$ & $\begin{array}{c}1.5 \\
(0.9-2.7)\end{array}$ \\
\hline $\begin{array}{l}\text { Population estimate, } \\
\text { millions }\left(95 \% \mathrm{Cl}^{\mathrm{b}}\right)\end{array}$ & $\begin{array}{c}3.9 \\
(3.0-4.8)\end{array}$ & $\begin{array}{c}0.7 \\
(0.5-1.0)\end{array}$ & $\begin{array}{c}1.3 \\
(0.8-1.9)\end{array}$ & $\begin{array}{c}1.6 \\
(1.1-2.0)\end{array}$ & $\begin{array}{c}0.1 \\
(0.05-0.2)\end{array}$ \\
\hline 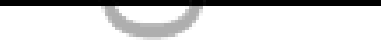 & \multicolumn{5}{|c|}{ n (column weighted percent [95\% Cl]) } \\
\hline Reside in nursing home & $\begin{array}{c}33 \\
(6.3[4.2-9.4])\end{array}$ & $\begin{array}{c}32 \\
(65.3[49.1-78.6)]\end{array}$ & $\begin{array}{c}33 \\
(53.1[31.3-73.7])\end{array}$ & $\begin{array}{c}44 \\
(52.7[34.6-70.1])\end{array}$ & $\begin{array}{c}6 \\
(39.7[18.3-65.9])\end{array}$ \\
\hline \multicolumn{6}{|l|}{ Dementia stage $^{\mathrm{C}}$} \\
\hline Mild & $\begin{array}{c}170 \\
(84.7[75.8-90.8])\end{array}$ & $\begin{array}{c}11 \\
(23.6[7.9-52.6])\end{array}$ & $\begin{array}{c}29 \\
(59.0[40.8-74.9])\end{array}$ & $\begin{array}{c}52 \\
(49.0[34.8-63.4])\end{array}$ & $\begin{array}{c}3 \\
(32.6[12.3-62.5])\end{array}$ \\
\hline Moderate & $\begin{array}{c}24 \\
(6.5[3.2-12.8)] \\
\end{array}$ & $\begin{array}{c}19 \\
(36.4[16.8-61.9]) \\
\end{array}$ & $\begin{array}{c}23 \\
(27.6[14.4-46.3])\end{array}$ & $\begin{array}{c}26 \\
(24.1[12.8-40.6])\end{array}$ & $\begin{array}{c}4 \\
(34.5[13.5-63.9])\end{array}$ \\
\hline Severe & $\begin{array}{c}39 \\
(8.8[4.8-15.4)]\end{array}$ & $\begin{array}{c}26 \\
(40.0[24.8-57.3])\end{array}$ & $\begin{array}{c}18 \\
(13.5[6.0-27.4])\end{array}$ & $\begin{array}{c}25 \\
(26.9[14.2-45.0])\end{array}$ & $\begin{array}{c}6 \\
(33.0[12.0-63.9])\end{array}$ \\
\hline $\begin{array}{l}\text { Cholinesterase Inhibitor } \\
\text { or memantine }\end{array}$ & $\begin{array}{c}29 \\
(14.1[7.2-26.9])\end{array}$ & $\begin{array}{c}18 \\
(38.4[18.3-63.3])\end{array}$ & $\begin{array}{c}12 \\
(17.8[7.8-35.7])\end{array}$ & $\begin{array}{c}23 \\
(34.4[19.0-54.0])\end{array}$ & $\begin{array}{c}4 \\
(30.3[9.6-64.0])\end{array}$ \\
\hline \multicolumn{6}{|l|}{$\begin{array}{l}\text { Other Psychotropic } \\
\text { Medication }\end{array}$} \\
\hline Antipsychotic & $\mathrm{n} / \mathrm{a}^{\mathrm{d}}$ & $\mathrm{n} / \mathrm{a}$ & $\begin{array}{c}16 \\
(20.0[9.1-38.5])\end{array}$ & $\begin{array}{c}20 \\
(20.5[10.1-37.0])\end{array}$ & $\begin{array}{c}7 \\
(37.0[17.0-62.7])\end{array}$ \\
\hline Sedative-hypnotic & $\mathrm{n} / \mathrm{a}$ & $\begin{array}{c}16 \\
(35.8[16.1-62.0])\end{array}$ & $\mathrm{n} / \mathrm{a}$ & $\begin{array}{c}20 \\
(26.1[14.4-42.6])\end{array}$ & $\begin{array}{c}6 \\
(43.1[12.8-79.6])\end{array}$ \\
\hline Antidepressant & $\mathrm{n} / \mathrm{a}$ & $\begin{array}{c}20 \\
(44.2[22.0-69.0])\end{array}$ & $\begin{array}{c}20 \\
(31.4[17.0-50.6])\end{array}$ & $\mathrm{n} / \mathrm{a}$ & $\begin{array}{c}8 \\
(47.8[24.9-71.7])\end{array}$ \\
\hline Mood Stabilizer & $\mathrm{n} / \mathrm{a}$ & $\begin{array}{c}7 \\
(5.2[2.1-12.5]) \\
\end{array}$ & $\begin{array}{c}6 \\
(3.4[1.0-10.4])\end{array}$ & $\begin{array}{c}8 \\
(3.1[1.3-7.4]) \\
\end{array}$ & $\mathrm{n} / \mathrm{a}$ \\
\hline
\end{tabular}

21

This article is protected by copyright. All rights reserved. 


\begin{tabular}{|c|c|c|c|c|c|} 
Any & n/a & 32 & 37 & 43 & 12 \\
& & $(65.1[42.9-82.3])$ & $(44.3[28.1-61.9])$ & $(44.7[29.3-61.3])$ & $(82.4[28.3-98.2])$ \\
\hline
\end{tabular}

${ }^{a}$ Medication groups are not mutually exclusive

${ }^{\mathrm{b}} \mathrm{Cl}$ : confidence interval

${ }^{c}$ As classified by Clinical Dementia Rating Scale (CDR) Score: Mild (CDR 0.5-1.0); Moderate (CDR 2.0); Severe (CDR 3.0-5.0)

${ }^{\mathrm{d}} \mathrm{n} / \mathrm{a}$ : not applicable

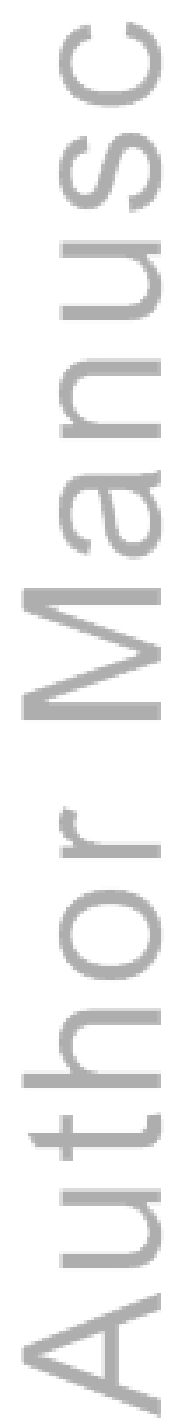


Table 2. Sample Characteristics of ADAMS Participants with Dementia

\begin{tabular}{|c|c|c|c|c|c|c|c|c|c|}
\hline \multirow{3}{*}{$\begin{array}{l} \\
\text { Age Group } \\
70-79(n, \text { weighted } \%)^{b}\end{array}$} & \multicolumn{2}{|c|}{$\begin{array}{c}(1) \\
\text { No medication } \\
\mathrm{n}=234\end{array}$} & \multicolumn{2}{|c|}{$\begin{array}{c}\text { (2) } \\
\text { Antipsychotic } \\
\mathrm{n}=62\end{array}$} & \multicolumn{2}{|c|}{$\begin{array}{c}(3) \\
\text { Sedative-hypnotic } \\
n=51\end{array}$} & \multicolumn{2}{|c|}{$\begin{array}{c}(4) \\
\text { Antidepressant } \\
n=67\end{array}$} & \multirow{4}{*}{ 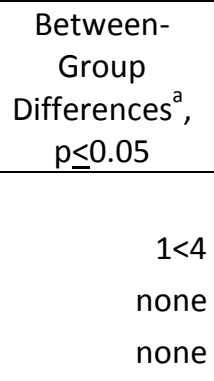 } \\
\hline & & & & & & & & & \\
\hline & 44 & 17.3 & 13 & 30.8 & 6 & 21.5 & 20 & 42.2 & \\
\hline $80-89$ & 125 & 65.0 & 30 & 52.7 & 27 & 63.3 & 33 & 44.0 & \\
\hline$\geq 90$ & 65 & 17.8 & 19 & 16.5 & 18 & 15.2 & 14 & 13.8 & \\
\hline Female & 151 & 66.0 & 46 & 72.6 & 35 & 71.3 & 46 & 69.5 & none \\
\hline \multirow{3}{*}{$\begin{array}{l}\text { Ethnicity } \\
\text { Non-Hispanic White } \\
\text { Non-Hispanic Black }\end{array}$} & \multirow{4}{*}{$\begin{array}{r}149 \\
64 \\
21 \\
\end{array}$} & \multirow{4}{*}{$\begin{array}{r}81.3 \\
14.6 \\
4.1\end{array}$} & \multirow{3}{*}{$\begin{array}{r}50 \\
9\end{array}$} & \multirow[b]{2}{*}{86.3} & \multirow[b]{2}{*}{36} & \multirow[b]{2}{*}{83.8} & \multirow[b]{2}{*}{50} & \multirow[b]{2}{*}{88.1} & \multirow[b]{2}{*}{ none } \\
\hline & & & & & & & & & \\
\hline & & & & 11.5 & 9 & 4.9 & 10 & 6.6 & $1>3,1>4$ \\
\hline Other & & & 3 & 2.2 & 6 & 11.3 & 7 & 5.3 & none \\
\hline Married & 63 & 34.6 & 17 & 26.0 & 10 & 12.5 & 19 & 23.3 & $1>3$ \\
\hline Lives in $\mathrm{NH}$ & 33 & 6.3 & 33 & 61.3 & 21 & 47.0 & 22 & 34.8 & $1<2,1<3,1<4$ \\
\hline \multicolumn{10}{|l|}{ Education } \\
\hline$<12 y$ & 138 & 45.7 & 34 & 48.2 & 32 & 42.9 & 39 & 50.5 & none \\
\hline HS graduate & 51 & 28.5 & 14 & 17.6 & 13 & 37.5 & 12 & 15.9 & none \\
\hline$>12 y$ & 45 & 25.8 & 14 & 34.2 & 6 & 19.6 & 16 & 33.6 & none \\
\hline \multicolumn{10}{|l|}{ Dementia diagnosis } \\
\hline$A D$ & 179 & 70.4 & 49 & 75.6 & 40 & 75.8 & 38 & 51.5 & none \\
\hline Vascular & 32 & 17.4 & 6 & 8.4 & 8 & 20.8 & 18 & 26.0 & $1>2$ \\
\hline Other & 23 & 12.2 & 7 & 16.0 & 3 & 3.4 & 11 & 22.5 & $1>3$ \\
\hline \multicolumn{10}{|l|}{ Dementia stage $^{c}$} \\
\hline Mild & 170 & 84.7 & 14 & 25.9 & 27 & 72.3 & 42 & 66.5 & $1>2,1>4$ \\
\hline Moderate & 24 & 6.5 & 21 & 36.5 & 13 & 16.8 & 14 & 11.7 & $1<2$ \\
\hline Severe & 39 & 8.8 & 27 & 37.6 & 11 & 10.9 & 11 & 21.8 & $1<2$ \\
\hline Seen a psychiatrist $^{\mathrm{d}}$ & 7 & 1.5 & 9 & 12.0 & 2 & 3.6 & 6 & 16.5 & $1<2,1<4$ \\
\hline \multicolumn{10}{|l|}{ Medical history } \\
\hline Stroke & 84 & 35.2 & 24 & 42.4 & 15 & 25.8 & 30 & 40.6 & none \\
\hline Fall & 108 & 47.5 & 35 & 56.4 & 26 & 62.3 & 35 & 46.2 & none \\
\hline Seizure disorder & 19 & 5.4 & 7 & 11.1 & 3 & 2.0 & 4 & 7.9 & none \\
\hline Hypertension & 148 & 68.6 & 35 & 44.6 & 31 & 73.0 & 46 & 67.4 & $1>2$ \\
\hline Heart disease & 40 & 22.1 & 12 & 14.4 & 8 & 14.3 & 21 & 35.9 & none \\
\hline Diabetes & 26 & 11.1 & 9 & 12.8 & 9 & 8.3 & 14 & 17.9 & none \\
\hline $\begin{array}{l}\text { Chronic respiratory } \\
\text { problem }\end{array}$ & 36 & 13.8 & 11 & 31.3 & 15 & 52.7 & 17 & 21.0 & $1<3$ \\
\hline Cancer & 67 & 30.1 & 16 & 20.2 & 20 & 41.8 & 16 & 13.2 & $1<4$ \\
\hline Major depressive episode & 45 & 16.1 & 26 & 48.9 & 17 & 39.6 & 46 & 66.1 & $1<2,1<4$ \\
\hline Bipolar disorder & 1 & 0.3 & 1 & 1.0 & 0 & 0.0 & 0 & 0.0 & none \\
\hline Schizophrenia & 0 & 0.0 & 2 & 11.6 & 1 & 1.1 & 1 & 3.9 & none \\
\hline Alcohol use & 138 & 68.5 & 30 & 50.3 & 26 & 46.5 & 31 & 52.9 & none \\
\hline Tobacco use & 106 & 50.5 & 26 & 39.7 & 22 & 52.8 & 27 & 52.0 & none \\
\hline $\begin{array}{l}\text { Total number of } \\
\text { medications (mean, SEM }{ }^{\mathrm{e}} \text { ) }\end{array}$ & 5.7 & 0.3 & 10.6 & 1.1 & 10.2 & 1.2 & 10.4 & 0.8 & $1<2,1<3,1<4$ \\
\hline
\end{tabular}




\begin{tabular}{|c|c|c|c|c|c|c|c|c|c|}
\hline MMSE $^{f}$ (mean, SEM) & 19.2 & 0.7 & 13.2 & 1.4 & 17.4 & 0.8 & 17.6 & 1.1 & $1>2$ \\
\hline NPI total ${ }^{g, h}$ (mean, SEM) & 4.5 & 1.0 & 12.6 & 2.1 & 11.8 & 3.9 & 6.9 & 1.1 & $1<2,1<3$ \\
\hline \multicolumn{10}{|l|}{ NPI category ${ }^{g}$} \\
\hline 1-2 domains & 69 & 28.6 & 25 & 32.0 & 17 & 33.5 & 25 & 51.6 & $1<4$ \\
\hline$\geq 3$ domains & 42 & 13.2 & 24 & 45.5 & 15 & 36.5 & 21 & 27.2 & $1<2,1<3$ \\
\hline
\end{tabular}

${ }^{a}$ Medication groups are mutually exclusive. The right-most column indicates whether a characteristic for a medication group differs in a statistically significant fashion $(p \leq 0.05)$ from the no medication group. For example, a smaller proportion of nonmedication users (1) were in the youngest age bracket compared to antidepressant users (4), represented as " $1<4$ ".

${ }^{\mathrm{b}}$ Cells indicate $\mathrm{n}$ and weighted percent within each respective medication group (column) unless noted otherwise.

${ }^{c}$ As classified by Clinical Dementia Rating Scale (CDR) Score: Mild (CDR 0.5-1.0); Moderate (CDR 2.0); Severe (CDR 3.0-5.0); $\mathrm{n}=413$

${ }^{d} \mathrm{n}=354$

e SEM: standard error of the mean

f $\mathrm{n}=371$; range $0-30$

${ }^{\mathrm{g}} \mathrm{n}=400$

$\mathrm{h}$ range: $0-120$

' range: 0-50 
Figure 1. Estimated Prevalence of Neuropsychiatric Symptoms by Medication Group ${ }^{\mathrm{a}}$

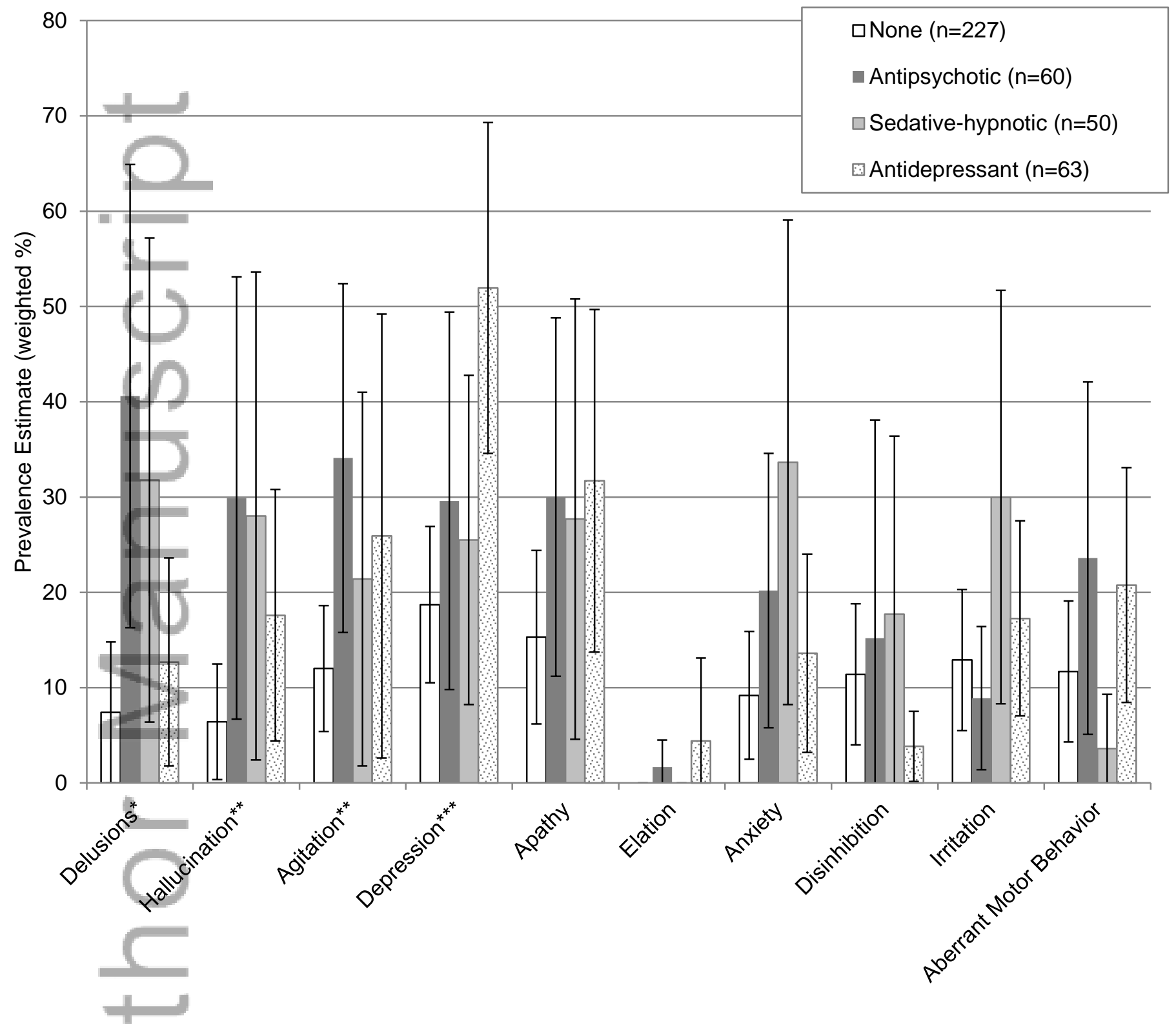

${ }^{a}$ Medication groups are mutually exclusive.

${ }^{\mathrm{b}}$ Brackets indicate $95 \%$ confidence intervals.

* Antipsychotic $>$ none, sedative-hypnotic $>$ none; $p<0.05$ 
** Antipsychotic $>$ none; $p<0.05$

*** Antidepressant $>$ none; $p<0.05$

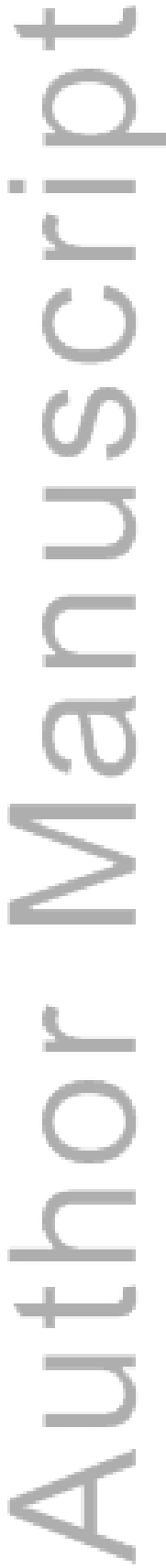


Table 3. Association of Overall Neuropsychiatric Symptom Prevalence with Psychotropic Use ${ }^{a}$

\begin{tabular}{|c|c|c|c|c|c|c|c|c|c|c|c|c|}
\hline \multirow{2}{*}{$=\frac{O}{\mathrm{~S}}$} & \multicolumn{4}{|c|}{ Antipsychotic $(n=286)$} & \multicolumn{4}{|c|}{ Sedative-hypnotic $(n=276)$} & \multicolumn{4}{|c|}{ Antidepressant $(n=289)$} \\
\hline & $\begin{array}{c}\text { Adjusted }^{b} \\
\text { OR } \\
(95 \% \mathrm{Cl}) \\
\end{array}$ & $\begin{array}{c}\mathrm{P} \\
\text { value }\end{array}$ & $\begin{array}{c}\text { Adjustedc } \\
\text { OR } \\
(95 \% \mathrm{Cl}) \\
\end{array}$ & $\begin{array}{c}P \\
\text { value }\end{array}$ & $\begin{array}{c}\text { Adjustedb } \\
\text { OR } \\
(95 \% \mathrm{Cl}) \\
\end{array}$ & $\begin{array}{c}P \\
\text { value }\end{array}$ & $\begin{array}{c}\text { Adjustedc } \\
\text { OR } \\
(95 \% \mathrm{Cl}) \\
\end{array}$ & $\begin{array}{c}P \\
\text { value }\end{array}$ & $\begin{array}{c}\text { Adjusted }^{b} \\
\text { OR } \\
(95 \% \mathrm{Cl}) \\
\end{array}$ & $\begin{array}{c}\mathrm{P} \\
\text { value }\end{array}$ & $\begin{array}{c}\text { Adjustedc } \\
\text { OR } \\
(95 \% \mathrm{Cl}) \\
\end{array}$ & $\begin{array}{c}\mathrm{P} \\
\text { value }\end{array}$ \\
\hline Neuropsychiatric Inventor) & & & & & & & & & & & & \\
\hline $\begin{array}{l}\text { Domains } \\
0\end{array}$ & ref & & ref & & ref & & ref & & ref & & ref & \\
\hline $1-2$ & $\begin{array}{c}2.54 \\
(0.85-7.58)\end{array}$ & 0.09 & $\begin{array}{c}2.28 \\
(0.66-7.84)\end{array}$ & 0.18 & $\begin{array}{c}2.24 \\
(0.52-9.56)\end{array}$ & 0.19 & $\begin{array}{c}1.94 \\
(0.37-10.14)\end{array}$ & 0.42 & $\begin{array}{c}4.62 \\
(1.60-13.34)\end{array}$ & 0.006 & $\begin{array}{c}3.63 \\
(1.21-10.89)\end{array}$ & 0.02 \\
\hline$\geq 3$ & $\begin{array}{c}7.40 \\
(2.46-22.24)\end{array}$ & 0.001 & $\begin{array}{c}3.91 \\
(1.60-9.56)\end{array}$ & 0.004 & $\begin{array}{c}5.20 \\
(1.74-15.55)\end{array}$ & 0.005 & $\begin{array}{c}3.84 \\
(0.93-15.87)\end{array}$ & 0.06 & $\begin{array}{c}5.36 \\
(2.04-14.05)\end{array}$ & 0.001 & $\begin{array}{c}4.11 \\
(1.32-12.81)\end{array}$ & 0.02 \\
\hline $\begin{array}{l}\text { Resides in nursing home } \\
\text { (ref: no) }\end{array}$ & & & $\begin{array}{c}8.96 \\
(4.19-19.18)\end{array}$ & $<0.001$ & & & $\begin{array}{c}15.59 \\
(5.08-47.80)\end{array}$ & $<0.001$ & & & $\begin{array}{c}11.23 \\
(3.57-35.59)\end{array}$ & $<0.001$ \\
\hline $\begin{array}{l}\text { Dementia Stage } \\
\text { Mild }\end{array}$ & & & ref & & & & ref & & & & ref & \\
\hline Moderate & & & $\begin{array}{c}7.09 \\
(1.85-27.13)\end{array}$ & 0.006 & & & $\begin{array}{c}1.27 \\
(0.29-5.48)\end{array}$ & 0.74 & & & $\begin{array}{c}2.68 \\
(0.93-7.77)\end{array}$ & 0.07 \\
\hline Severe & & & $\begin{array}{c}3.56 \\
(1.24-10.18) \\
\end{array}$ & 0.02 & & & $\begin{array}{c}0.42 \\
(0.08-2.33) \\
\end{array}$ & 0.31 & & & $\begin{array}{c}1.29 \\
(0.34-4.90)\end{array}$ & 0.70 \\
\hline
\end{tabular}

${ }^{a}$ Odds ratio (OR) reflects odds of medication use relative to the no medication group. Medication groups are mutually exclusive.

${ }^{\mathrm{b}}$ Adjusted for age (linear term), gender, and survey year.

${ }^{c}$ Adjusted for age (linear term), gender, survey year, nursing home residence, and dementia stage. 
Table 4. Association of Neuropsychiatric Symptom Domain Clusters and Associated Caregiver Distress with Psychotropic Use ${ }^{\mathrm{a}}$

\begin{tabular}{|c|c|c|c|c|c|c|}
\hline & \multicolumn{2}{|c|}{ Antipsychotic $(n=286)$} & \multicolumn{2}{|c|}{ Sedative-hypnotic $(n=276)$} & \multicolumn{2}{|c|}{ Antidepressant $(n=289)$} \\
\hline Domain Cluster & $\begin{array}{c}\text { Adjusted }^{\mathrm{b}} \\
\text { OR }(95 \% \mathrm{Cl})\end{array}$ & $P$ value & $\begin{array}{c}\text { Adjusted }^{\mathrm{b}} \\
\text { OR }(95 \% \mathrm{Cl})\end{array}$ & $P$ value & $\begin{array}{c}\text { Adjusted }^{\mathrm{b}} \\
\text { OR }(95 \% \mathrm{Cl})\end{array}$ & $\mathrm{P}$ value \\
\hline $\begin{array}{l}\text { Delusions + } \\
\text { Hallucinations }+ \\
\text { Agitationc }^{c}\end{array}$ & $\begin{array}{c}1.12 \\
(1.00-1.24)\end{array}$ & 0.04 & $x$ & $x$ & $\mathrm{x}$ & $\mathrm{x}$ \\
\hline Caregiver distress $^{d}$ & $\begin{array}{c}0.99 \\
(0.80-1.24) \\
\end{array}$ & 0.96 & $X$ & $\mathrm{X}$ & $X$ & $x$ \\
\hline $\begin{array}{l}\text { Anxiety + } \\
\text { Agitation }\end{array}$ & $\mathrm{X}$ & $\mathrm{x}$ & $\begin{array}{c}1.28 \\
(1.06-1.55)\end{array}$ & 0.01 & $\mathrm{X}$ & $\mathrm{x}$ \\
\hline Caregiver distress $^{d}$ & $x$ & $x$ & $\begin{array}{c}0.89 \\
(0.71-1.12) \\
\end{array}$ & 0.31 & $x$ & $x$ \\
\hline $\begin{array}{l}\text { Depression + } \\
\text { Apathy }^{\mathrm{c}}\end{array}$ & $x$ & $\mathrm{X}$ & $\mathrm{X}$ & $\mathrm{X}$ & $\begin{array}{c}0.97 \\
(0.87-1.08)\end{array}$ & 0.52 \\
\hline Caregiver distress $^{\mathrm{d}}$ & $\mathrm{X}$ & $x$ & $X$ & $X$ & $\begin{array}{c}1.22 \\
(0.99-1.50) \\
\end{array}$ & 0.07 \\
\hline $\begin{array}{l}\text { Resides in nursing } \\
\text { home (ref: no) }\end{array}$ & $\begin{array}{c}9.47 \\
(4.48-20.03)\end{array}$ & $<0.001$ & $\begin{array}{c}12.94 \\
(4.43-37.78)\end{array}$ & $<0.001$ & $\begin{array}{c}14.62 \\
(4.53-47.19)\end{array}$ & $<0.001$ \\
\hline $\begin{array}{l}\text { Dementia Stage } \\
\text { Mild }\end{array}$ & ref & & ref & & ref & \\
\hline Moderate & $\begin{array}{c}6.90 \\
(2.15-22.12)\end{array}$ & 0.002 & $\begin{array}{c}1.32 \\
(0.37-4.76)\end{array}$ & 0.66 & $\begin{array}{c}2.74 \\
(0.88-8.51)\end{array}$ & 0.08 \\
\hline Severe & $\begin{array}{c}3.29 \\
(1.08-10.00) \\
\end{array}$ & 0.04 & $\begin{array}{c}0.39 \\
(0.09-1.59) \\
\end{array}$ & 0.18 & $\begin{array}{c}1.51 \\
(0.34-6.65) \\
\end{array}$ & 0.57 \\
\hline
\end{tabular}

${ }^{a}$ Odds ratio reflects odds of medication use relative to the no medication group. Medication groups are mutually exclusive.

${ }^{\mathrm{b}}$ Adjusted for age (linear term), gender, survey year, nursing home residence, and dementia stage.

${ }^{\mathrm{c}}$ Domain cluster variable is continuous and derived by adding the NPI scores for each domain listed in the cell. Odds ratio reflects the odds of medication associated with 1 additional NPI point from domains represented.

${ }^{d}$ Caregiver distress variable is continuous and derived by adding the NPI caregiver distress scores for the respective participant domains.

This article is protected by copyright. All rights reserved. 


\section{REFERENCES}

American Geriatrics Society 2015 Beers Criteria Update Expert Panel. 2015. American

Geriatrics Society 2015 updated Beers Criteria for potentially inappropriate medication

use in older adults. J Am Geriatr Soc. Epub ahead of print: DOI: 10.1111/jgs.13702.

Banerjee S, Hellier J, Dewey M, Romeo R, Ballard C, Baldwin R, Bentham P, Fox C, Holmes C

$=$ = \& Katona C. 2011. Sertraline or mirtazapine for depression in dementia (hta-sadd): A randomised, multicentre, double-blind, placebo-controlled trial. The Lancet 378: 403-

411.

Beers MH. 1997. Explicit criteria for determining potentially inappropriate medication use by the elderly: An update. Arch Intern Med 157: 1531-1536.

Cummings JL. 1997. The neuropsychiatric inventory assessing psychopathology in dementia patients. Neurology 48: 10S-16S.

Folstein MF, Folstein SE \& Mchugh PR. 1975. "Mini-mental state". A practical method for grading the cognitive state of patients for the clinician. J Psychiatr Res 12: 189-198.

Heeringa SG, Fisher GG, Hurd MD, Langa KM, Ofstedal BM, Plassman BL, Rodgers WL, \& Weir DR. 2009. Aging, Demographics, and Memory Study (ADAMS). Sample design, weighting, and analysis for ADAMS.

http://hrsonline.isr.umich.edu/sitedocs/userg/ADAMS SampleWeights_Jun2009.pdf Accessed October 15, 2014.

Huybrechts KF, Rothman KJ, Silliman RA, Brookhart MA \& Schneeweiss S. 2011. Risk of death and hospital admission for major medical events after initiation of psychotropic medications in older adults admitted to nursing homes. CMAJ 183: E411-9. 
Gruber-Baldini AL, Stuart B, Zuckerman IH, Simoni-Wastila L \& Miller R. 2007. Treatment of dementia in community-dwelling and institutionalized medicare beneficiaries. J Am Geriatr Soc 55: 1508-1516.

Kales HC, Gitlin LN \& Lyketsos CG. 2015. Assessment and management of behavioral and psychological symptoms of dementia. BMJ 350: h369.

Kales HC, Kim HM, Zivin K, Valenstein M, Seyfried LS, Chiang C, Cunningham F, Schneider LS \& Blow FC. 2012. Risk of mortality among individual antipsychotics in patients with dementia. Am J Psychiatry 169: 71-79.

Kales HC, Zivin K, Kim HM, Valenstein M, Chiang C, Ignacio RV, Ganoczy D, Cunningham F, Schneider LS \& Blow FC. 2011. Trends in antipsychotic use in dementia 1999-2007. Arch Gen Psychiatry 68: 190-197.

Landes AM, Sperry SD, Strauss ME \& Geldmacher DS. 2001. Apathy in alzheimer's disease. J Am Geriatr Soc 49: 1700-1707.

Langa KM, Plassman BL, Wallace RB, Herzog AR, Heeringa SG, Ofstedal MB, Burke JR, Fisher GG, Fultz NH, Hurd MD, Potter GG, Rodgers WL, Steffens DC, Weir DR \& Willis RJ. 2005. The aging, demographics, and memory study: Study design and methods. Neuroepidemiology 25: 181-191.

Lyketsos CG, Carrillo MC, Ryan JM, Khachaturian AS, Trzepacz P, Amatniek J, Cedarbaum J, Brashear R \& Miller DS. 2011. Neuropsychiatric symptoms in alzheimer's disease.

Alzheimer's \& Dementia 7: 532-539.

Lyketsos CG, Lopez O, Jones B, Fitzpatrick AL, Breitner J \& Dekosky S. 2002. Prevalence of neuropsychiatric symptoms in dementia and mild cognitive impairment. JAMA 288:

1475-1483.

This article is protected by copyright. All rights reserved. 
Lyketsos CG, Steinberg M, Tschanz JT, Norton MC, Steffens DC \& Breitner JC. 2000. Mental and behavioral disturbances in dementia: Findings from the cache county study on memory in aging. Am J Psychiatry 157: 708-714.

Maust DT, Kim HM, Seyfried LS, Chiang C, Kavanagh J, Schneider LS \& Kales HC. 2015.

Antipsychotics, other psychotropics, and the risk of death in patients with dementia:

= Number needed to harm. JAMA Psychiatry 72: 438-445.

Maust DT, Mavandadi S, Eakin A, Streim JE, Difillipo S, Snedden T \& Oslin DW. 2011.

Telephone-based behavioral health assessment for older adults starting a new psychiatric medication. Am J Geriatr Psychiatry 19: 851-858.

McKhann G, Drachman D, Folstein M, Katzman R, Price D \& Stadlan EM. 1984. Clinical diagnosis of alzheimer's disease report of the nincds- adrda work group* under the auspices of department of health and human services task force on alzheimer's disease.

Neurology 34: 939-939.

Morris JC. 1993. The clinical dementia rating (CDR): Current version and scoring rules.

Neurology 43: 2412-2414.

Okura T \& Langa KM. 2011. Caregiver burden and neuropsychiatric symptoms in older adults with cognitive impairment: The aging, demographics, and memory study (adams). Alzheimer Dis Assoc Disord 25: 116-21.

Okura T, Plassman BL, Steffens DC, Llewellyn DJ, Potter GG \& Langa KM. 2010. Prevalence of -neuropsychiatric symptoms and their association with functional limitations in older adults in the united states: The aging, demographics, and memory study. J Am Geriatr Soc 58: $330-337$. 
Olfson M, Blanco C, Liu SM, Wang S \& Correll CU. 2012. National trends in the office-based treatment of children, adolescents, and adults with antipsychotics. Arch Gen Psychiatry 69: 1247-1256.

Paulose- Ram R, Safran MA, Jonas BS, Gu Q \& Orwig D. 2007. Trends in psychotropic medication use among us adults. Pharmacoepidemiol Drug Saf 16: 560-570.

Plassman BL, Langa KM, Fisher GG, Heeringa SG, Weir DR, Ofstedal MB, Burke JR, Hurd MD, Potter GG, Rodgers WL, Steffens DC, Mcardle JJ, Willis RJ \& Wallace RB. 2008.

Prevalence of cognitive impairment without dementia in the United States. Ann Intern

Med 148: 427-434.

Plassman BL, Langa KM, Fisher GG, Heeringa SG, Weir DR, Ofstedal MB, Burke JR, Hurd MD, Potter GG, Rodgers WL, Steffens DC, Willis RJ \& Wallace RB. 2007. Prevalence of dementia in the United States: The Aging, Demographics, and Memory Study.

Neuroepidemiology 29: 125-132.

Plassman BL, Langa KM, Mccammon RJ, Fisher GG, Potter GG, Burke JR, Steffens DC, Foster NL, Giordani B, Unverzagt FW, Welsh-Bohmer KA, Heeringa SG, Weir DR \& Wallace RB. 2011. Incidence of dementia and cognitive impairment, not dementia in the United States. Ann Neurol 70: 418-426.

Porsteinsson AP, Drye LT, Pollock BG, Devanand DP, Frangakis C, Ismail Z, Marano C, Meinert CL, Mintzer JE, Munro CA, Pelton G, Rabins PV, Rosenberg PB, Schneider LS, Shade DM, Weintraub D, Yesavage J, Lyketsos CG \& Cit ADRG. 2014. Effect of citalopram on agitation in Alzheimer disease: The citAD randomized clinical trial. JAMA 311: $682-691$. 
Rhee Y, Csernansky J, Emanuel L, Chang C \& Shega J. 2011. Psychotropic medication burden and factors associated with antipsychotic use: An analysis of a population- based sample of community- dwelling older persons with dementia. J Am Geriatr Soc 59: 2100-2107.

Rockwood K, Howlett SE, Macknight C, Beattie BL, Bergman H, Hébert R, Hogan DB, Wolfson

= C \& Mcdowell I. 2004. Prevalence, attributes, and outcomes of fitness and frailty in community-dwelling older adults: Report from the canadian study of health and aging. The Journals of Gerontology Series A: Biological Sciences and Medical Sciences 59: 1310-1317.

Román GC, Tatemichi TK, Erkinjuntti T, Cummings J, Masdeu J, Garcia JA, Amaducci L, Orgogozo J-M, Brun A \& Hofman A. 1993. Vascular dementia diagnostic criteria for research studies: Report of the NINDS- AIREN international workshop^. Neurology 43: $250-250$.

Rosenberg PB, Martin BK, Frangakis C, Mintzer JE, Weintraub D, Porsteinsson AP, Schneider LS, Rabins PV, Munro CA \& Meinert CL. 2010. Sertraline for the treatment of depression in Alzheimer disease. Am J Geriatr Psychiatry 18: 136-145.

Schnaider Beeri M, Werner P, Davidson M \& Noy S. 2002. The cost of behavioral and psychological symptoms of dementia (bpsd) in community dwelling Alzheimer's disease patients. Int J Geriatr Psychiatry 17: 403-408.

Schneider LS, Dagerman KS \& Insel P. 2005. Risk of death with atypical antipsychotic drug treatment for dementia: Meta-analysis of randomized placebo-controlled trials. JAMA 294: 1934-1943. 
Schneider LS, Tariot PN, Dagerman KS, Davis SM, Hsiao JK, Ismail MS, Lebowitz BD, Lyketsos CG, Ryan JM, Stroup TS, Sultzer DL, Weintraub D, Lieberman JA \& Group CaDS. 2006. Effectiveness of atypical antipsychotic drugs in patients with alzheimer's disease. N Engl J Med 355: 1525-1538.

Sonnega A, Faul JD, Ofstedal MB, Langa KM, Phillips JW \& Weir DR. 2014. Cohort profile: The

= Health and Retirement Study (HRS). Int J Epidemiol 43: 576-585.

Takayanagi Y, Spira AP, Bienvenu OJ, Hock RS, Carras MC, Eaton WW \& Mojtabai R. 2015.

Antidepressant use and lifetime history of mental disorders in a community sample:

Results from the Baltimore Epidemiologic Catchment Area Study. J Clin Psychiatry 76:

40-44.

Taylor DH, Østbye T, Langa KM, Weir D \& Plassman BL. 2009. The accuracy of medicare claims as an epidemiological tool: The case of dementia revisited. J Alzheimers Dis 17: 807-815.

Tell GS, Fried LP, Hermanson B, Manolio TA, Newman AB \& Borhani NO. 1993. Recruitment of adults 65 years and older as participants in the Cardiovascular Health Study. Ann Epidemiol 3: 358-366.

US Food and Drug Administration. 2005. Information for healthcare professionals: Information on conventional antipsychotics. US Department of Health and Human Services. http://www.fda.gov/Drugs/DrugSafety/ucm124830.htm. Accessed February 2, 2014. US Government Accountability Office. 2015. Antipsychotic Drug Use: HHS has initiatives to reduce use among older adults in nursing homes, but should expand efforts to other settings. http://www.gao.gov/assets/670/668221.pdf. Accessed April 2, 2015.

This article is protected by copyright. All rights reserved. 
Wang PS, Bohn RL, Glynn RJ, Mogun H \& Avorn J. 2001. Hazardous benzodiazepine regimens in the elderly: Effects of half-life, dosage, and duration on risk of hip fracture. Am J Psychiatry 158: 892-898.

Yaffe K, Fox P, Newcomer R, Sands L, Lindquist K, Dane K \& Covinsky KE. 2002. Patient and caregiver characteristics and nursing home placement in patients with dementia. JAMA

$=287: 2090-7$.

1

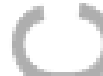

$\infty$
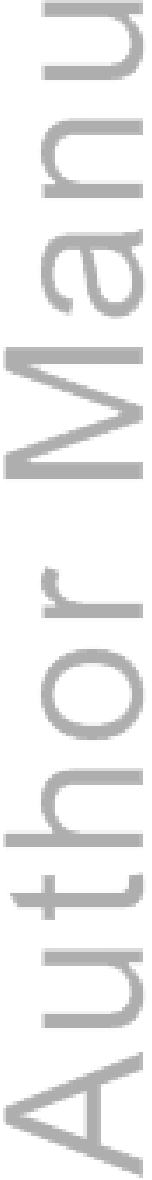